\title{
Decision Drivers for Search Engine Usage - The Mediating and Moderating Role of Lock-in Effects
}

\author{
Ingo Knuth ${ }^{1} \&$ Janina Masuhr $^{1}$ \\ 1 Department of Management \& Business Studies, HMKW Hochschule für Medien, Kommunikation und \\ Wirtschaft, Berlin, Germany \\ Correspondence: Ingo Knuth, Department of Management \& Business Studies, HMKW Hochschule für Medien, \\ Kommunikation und Wirtschaft, Ackerstr. 76, 13355 Berlin. Germany. E-mail: i.knuth@hmkw.de
}

Received: December 30, 2020

Accepted: May 25, 2021

Online Published: September 17, 2021

doi:10.5539/ijbm.v16n10p86

URL: https://doi.org/10.5539/ijbm.v16n10p86

\begin{abstract}
This study analyzes the central factors influencing the satisfaction and future use of search engines. It examines the influence of technological lock-in effects (e. g. operating systems / browsers providing pre-settings), as well as basic product- and brand-related factors (e. g. search results, user experience, brand image). Data was collected via a quantitative online survey in Germany, which resulted in 236 respondents providing statements about their most recently used search engine. The data shows that all independent variables have a strong impact on the satisfaction with a search engine as well as future usage and explain a lot of the variance of the dependent variables. The satisfaction with the core product has the strongest impact, followed by brand-related aspects and user experience. The results also show an impact of a search engine preset in the browser effects that influences the role of brand and the evaluation of different product characteristics.
\end{abstract}

Keywords: search engines, product quality, user experience, customer satisfaction, customer loyalty, structural equation model

\section{Introduction}

Search engines are a high priority for Internet users in answering questions, generating entertainment offers, conducting product research, and for making purchases (Lewandowski, 2015). About $90 \%$ of the German speaking population of Germany, 14 years and older, was online in 2019, and most had used search engines at least occasionally (ARD-ZDF-Forschungs kommission, 2020). In this context Google is the dominant option in most countries. Google's market share at the end of 2019 was around 93\%, followed by Bing, and Yahoo (Stat Counter, 2020). All other options combined equal just about 2.5 percent. Many scientists are trying to find an explanation for this phenomenon of "absolute market power", and possible remedies because search engine users are "locked into" a situation where the industry structures, technological infrastructures, vertical and lateral integration strategies, and brand strength of large companies, all inhibit competition in those markets, thereby limiting opportunities for consumer choice.

In this context several studies focus on the factors determining product quality and brand strength, but also raise the question of political intervention (e. g. cartel restrictions), as a solution for limited competition (Paal, 2013; Jansen et al., 2007). The central focus of research is the evaluation of information, seeking performance and the quality of search results (e. g. Höchstötter \& Koch, 2009; Jansen et al., 2009; Lewandowski, 2013 Schäfer et al., 2015). Only a few studies are focusing more on the general analysis of individual decision drivers of user search engine choice, by integrating product, brand, and consumer specific factors (Sirdeshmukh et al. 2018; Palanisamy 2013). Palanisamy (2013), for instance, proposes a model which includes many relevant factors for evaluating a search engine, such as: perceived product efficiency, (e. g. usability / ease of use), product effectiveness, (e. g. relevance of the search results), technology (e. g. user experience, browser used), and brand-related factors. Within this context, the authors state that "most of the search engines have similar layout and functions so brand plays an important role" (Palanisamy, 2013, p. 4).

The empirical investigation of these different consumer perspectives, and thereby the empirical evaluation of influencing factors of the individual decision for or against using a search machine, are implemented only in extracts. Some scholars are investigating the factors influencing user intention to adopt alternative search engines. Palos-Sanchez et al. (2018), are integrating aspects of product efficiency, (perceived usefulness, perceived ease of 
use), in addition to trust, as one brand-related factor with an indirect influence on the intention to use an alternative search engine. Reyes-Menendez et al. (2018) are assuming autonomous and planned consumer decision making and are, therefore, focusing on individuals, and factors such as social influence and habits, as well as product and brand specific factors, such as effort expectancy and trust.

However, these studies focus primarily on clearly observable, product-related factors having a direct influence on the quality perception of a search engine. Additional indirect factors that can trigger so-called lock-in effects, such as the role of brand perception and technological integration in existing infrastructures, (e. g., browsers), are not considered comprehensively enough. To fill this gap, we have conducted a structural equation model, based on data gathered in a quantitative survey among search engine users in Germany. Based upon core elements of the service value chain, and earlier studies about search engine usage, we developed a model to evaluate the impact of the independent variables, such as "product", "user experience," and "brand," on customer satisfaction and loyalty. In addition, questions about if the search engine had been pre-set in the Internet browser, and which operating system is used have been integrated into our model.

Furthermore, we have tested for the impact of the infrastructure, by comparing users that had a search engine preset in their Internet browser, and those that had not. The results show the impact of the brand on satisfaction and future usage is higher in the group of users that did not have a pre-set and, thus, could make a freer choice based on brand characteristics. Within the group of users with a preset, the impact of product characteristics and user experience is much greater.

In essence, we show that lock-in effects, based on brand perceptions and technological infrastructures, do have a significant impact on satisfaction with a search engine and intended usage. On this basis, it can be argued that choice of a search engine is only partly determined by observable product characteristics. Aspects influenced by market characteristics, such as brand features and technological integration, also have great impact.

\section{Hypothesis Development and Measurement}

Users' satisfaction with both a search engine and with future usage depends on many different factors, which can be identified on several levels. The perspective of classical service marketing is helpful here. First and in particular, product, price, communication, and distribution policies must be integrated, since these are regarded as key variables influencing both customer satisfaction and loyalty (McCarthy, 1960; Heskett et al., 1997). Second, the drivers of satisfaction and future usage in the search engine market can be substantiated, by examining aspects such as user guidance, brand awareness, and additional services (Lewandowski, 2014). Satisfaction with the core product, which is the perceived quality of the search results, plays a central role (Lewandowski, 2014). The third perspective examines industry structure. Since search engine markets tend to be highly concentrated, and companies provide self-contained infrastructures, (including search engines, operating systems, and browsers), consumer freedom of choice is limited, and therefore, may specially determine the future use of search engines. (Fahrig, 2014).

We investigate the impact lock-in effects have on the satisfaction with a search engine, as well as the willingness to use it in the future. These lock-in effects can be enabled by: 1) brand characteristics driven by earlier experience, (e. g. trust, loyalty) and 2) infrastructure-related aspects, (e. g. operating systems / browsers with pre-settings).

Our investigation contributes to current research, since existing studies tend to focus on description of search engine performance from a product performance perspective (Lewandowski \& Höchstötter, 2007; Lewandowski, 2013; Lewandowski, 2014). Some studies show that the larger and more diverse the product a search engine offers, the greater is its tendency to be used (Lewandowski \& Höchstötter, 2007; Everhart, 2014). Others consider user experience as a decisive factor for choice of a search engine (Speicher et al., 2015; Quirmbach, 2012; Lewandowski \& Höchstötter, 2007). Few publications regard brand image to have an influence on the willingness to use search engines (Bailey et al., 2007; Jansen et al., 2007; Jansen et al., 2009; Keller, 1993; Schäfer et al., 2015). Studies that include brand perspective often integrate it in the evaluation of technical aspects, such as the perceived quality of search results. Aspects of technological infrastructure and the role of the brand have not, so far, been sufficiently integrated within quantitative user studies.

We argue, therefore, that current research lacks a general consumer based view, and that the integration of different decision drivers of search engine usage, such as product variety and quality, user experience and brand perception, as well as the technological infrastructure, (with a focus on the user perspective), would provide a more holistic approach.

For these reasons, the present study integrates various product and brand characteristics, based on established technology acceptance, and media usage models. As a theoretical basis before the survey, key factors of the "Uses 
and Gratifications Approach", and UTAUT are integrated and applied to the object of investigation.

According to the "Uses and Gratifications Approach", search engine users are looking for gratifications, and above all for the satisfaction of their needs (Katz \& Foulkes, 1962, p. 26). The probability of re-use increases if these needs are, indeed, satisfied (Rosengren et al., 1985). Accordingly, we assume that users actively receive media, and enjoy freedom of choice due to individual needs. It is also assumed that they are aware of their wishes and can articulate them (Katz et al., 1974; Hugger, 2008; Palmgreen \& Rayburn, 1982). If needs are not satisfied at the time of use, this has an impact on future usage choice.

Furthermore, the "Unified Theory of Acceptance and Use of Technology" helps to better understand the acceptance and use of different media technologies and products, by combining different dimensions of individual product benefits (Venkatesh et al., 2012; Peris \& Nüttgens, 2011). In this way, the consumer perspective is folded into the following dimensions: "performance expectancy", "effort expectancy", "social influence", "facilitating conditions", "hedonic motivation", "price value", and "habit" (Venkatesh et al., 2012). These aspects mainly refer to core product characteristics, and have already been applied to the case of search engine perception and usage (Palos-Sanchez et al. 2018).

The construct of product quality, regarding search engine usage, contains questions concerning the degree of satisfaction with the technical possibilities, the search results, and the product variety and filters offered (Aaker, 1996; Lewandowski, 2013; Palanisamy, 2013). Moreover, additional functions offered by search engine providers have been duly considered (Broschart, 2011; Lewandowski, 2013).

In order to attract users and convince them to spend more time on platforms, efficiency-related factors, such as website usability, play a crucial role (Palanisamy, 2013). We thus integrate the construct "user experience" taking into account various aspects based on UTAUT's theoretical considerations regarding "Effort Expectancy" and "Ease of Use", as well as various preliminary studies from search engine research (Venkatesh et al., 2012; Quirmbach, 2012; Lewandowski \& Höchstötter, 2007). “The relationship between text and image”, based on the work of Quirmbach, (2012), is, thus, taken into account. According to Lewandowski (2011), the ratio of advertisements to organic search results should also seem appropriate for the user and has, therefore, also been integrated. In addition, we consider whether the design appeals to and motivates the user to choose the search engine (Quirmbach, 2012). Based on the UTAUT according to Venkatesh et al. (2012), and specifically following Lewandowski and Höchstötter (2007), the comprehensibility of the structure of the search engine result page (SERP), is also examined.

According to Pauly-Grundmann (2010), brand policy plays a decisive role in the success of companies, including psychological factors such as trust, image, and brand loyalty. This specifically applies to the selection of the search engine as well as its general and element specific evaluation, (e. g. results page, link evaluation, and landing page evaluation), (Palanisamy, 2013). Concerning search engines, Schäfer et al (2015), focus on the importance of the brand versus performance. Additionally, the connection between willingness to use a brand and sympathy towards it has often been discussed in the literature and so has been integrated (Lewandowski, 2013; Jansen et al., 2009). According to Aaker (1996), both interest in the brand itself and future use also have an influence on overall satisfaction.

As a moderating variable, we questioned whether the commonly used search engine had already been pre-set in the Internet browser.

Finally, the aspects of satisfaction, recommendation, and future use were incorporated as dependent variables (Venkatesh et al., 2012).

Figure 1 shows the assumed direct relationships between all integrated variables.

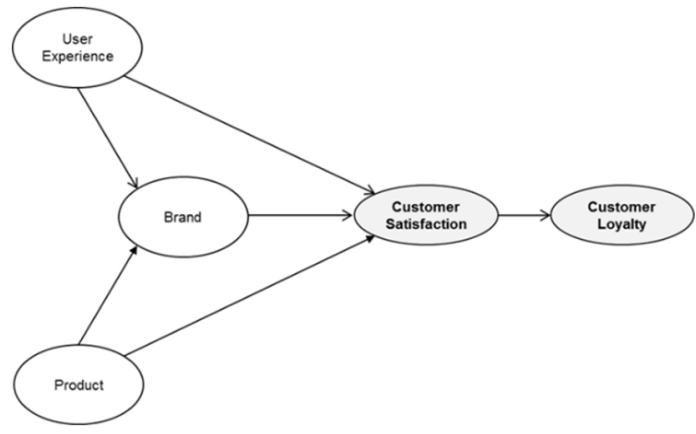

Figure 1. Basic research model 
Based on the factors and relationships mentioned above, the following key hypotheses are developed:

H1: User experience positively affects satisfaction.

H2: Product quality positively affects satisfaction.

H3: Brand reputation positively affects satisfaction.

H4: User experience positively affects brand reputation.

H5: Product quality positively affects brand reputation.

H6: Satisfaction positively affects loyalty.

H7: Brand reputation mediates user experience.

H8: Brand reputation mediates product quality.

H9: Browser preset moderates the impact of brand reputation.

H10: Browser preset moderates the impact of product quality.

H11: Browser preset moderates the impact of user experience.

Following established guidelines, tests for discriminant validity and cross-loading were conducted (Fornell \& Larcker, 1981; Wong, 2016; Henseler et al., 2015). As Tables 2 and 3 show, high validity of the measurement can be confirmed. All quality criteria, (Cronbach's alpha, average variance extracted, composite reliability), reported in the table are well accepted and indicate valid measurements (Bagozzi \& Yi, 1988; Chin, 1998; Lance et al., 2006; Nunnally, 1978).

Table 1. Measures of variables

\begin{tabular}{lcccccc}
\hline & $\boldsymbol{M}$ & $\boldsymbol{S D}$ & Loading & $\boldsymbol{\alpha}$ & $\boldsymbol{A V E}$ & $\boldsymbol{C R}$ \\
\hline $\begin{array}{l}\text { Customer Satisfaction: Reflective } \\
\text { 280 Overall satisfaction }\end{array}$ & 3.07 & 0.81 & 1.00 & & & \\
Customer Loyalty: Reflective & & & & 1.00 & 1.00 & 1.00 \\
281 Likelihood of recommendation & 2.89 & 1.00 & & & & \\
Product & & & 1.00 & 0.86 & 0.70 & 0.90 \\
207 Technical possibilities & 3.12 & 0.70 & 0.88 & & & \\
208 Search results & 3.01 & 0.74 & 0.82 & & & \\
209 Variety of products & 3.06 & 0.78 & 0.87 & & & \\
210 Filter & 2.87 & 0.81 & 0.79 & & & \\
User Experience & & & & & 0.84 \\
213 Effort to achieve goals & 3.20 & 0.77 & 0.73 & & & \\
214 Ratio of text to image & 3.17 & 0.72 & 0.74 & & & \\
216 Design appeal & 2.93 & 0.91 & 0.86 & & & \\
217 Design: motivation to use & 2.63 & 0.93 & 0.77 & & & \\
219 Structure: easy to use & 3.25 & 0.73 & 0.79 & & & \\
Brand & & & & 0.90 & 0.71 & \\
220 Trustworthy & 2.74 & 0.87 & 0.81 & & & \\
221 Likeable & 2.80 & 0.87 & 0.91 & & & \\
222 Interesting & 2.78 & 0.94 & 0.83 & & & \\
223 Loyalty & 2.24 & 1.02 & 0.78 & & & \\
224 Image positive & 2.74 & 0.91 & 0.90 & & &
\end{tabular}

As table 2 shows, all indicator loadings are higher than those of the other constructs.

Table 2. Discriminant validity

\begin{tabular}{llllll}
\hline & $(1)$ & $(2)$ & $(3)$ & $(4)$ & $(5)$ \\
\hline (1) Brand & 0.845 & & & & \\
(2) Product & 0.447 & 0.838 & & & \\
(3) Recommendation & 0.739 & 0.630 & 1.000 & & \\
(4) Satisfaction & 0.604 & 0.715 & 0.820 & 1.000 & \\
(5) UX & 0.574 & 0.733 & 0.691 & 0.715 & 0.782 \\
\hline
\end{tabular}




\section{Methodology}

\subsection{Sample}

The data was gathered in November and December, 2018. The survey had been distributed via campus management systems of universities in Berlin, Germany, as well as online networks. In our online survey, we asked 236 search engine users in Germany to rate the one they are using. In this case, we included Google, Bing, and Ecosia. Since many respondents use more than one search engine, different products could have been assessed. Based on the 236 participants, we generated 386 ratings for different search engines. The sample consists primarily of younger Internet users from 18 to 29 years of age (82 percent). In addition, a large, increased participation of women can be observed. Roughly 96 percent use search engines daily, or several times a week. Google predominates with 97.5 percent, followed by Bing, 42.4 percent, Yahoo, 32.5 percent, and Web.de, 19.5 percent. Due to the situation in the German markets, and to limit the number of ratings per respondent, we asked for evaluation of Google $(n=230)$, Bing $(n=100)$, and Ecosia $(n=56)$.

Table 3: Profile of respondents

\begin{tabular}{lll}
\hline Variable & Frequency & $\%$ of total \\
\hline Age & & \\
$18-29$ y. & 193 & $81.8 \%$ \\
$>30$ y. & 43 & $18.2 \%$ \\
Gender & & \\
Male & 75 & 31.8 \\
Female & 159 & 67.4 \\
Search Engine Usage & & \\
$>$ Daily & 201 & 85.2 \\
$>$ Weekly & 26 & 11.0 \\
Once per week & 3 & 1.3 \\
Less often & 6 & 2.5 \\
Search Engine Used & & \\
Google & 230 & 97.5 \\
Bing & 100 & 42.4 \\
Ecosia & 56 & 24.3 \\
Web.de & 46 & 19.5 \\
Yahoo & 83 & 32.2 \\
Other & 8 & 3.4 \\
\hline
\end{tabular}

\section{Results}

To calculate our theoretical model, we used the partial least squares approach and the Smart PLS calculation software (Ringle et al., 2020). The model included all constructs, including the reflective items displayed in table 2. The results of the general analysis are reported in Table 4. Our model explains $63.7 \%$ (adjusted $\mathrm{R}^{2}$ ) of the variance in the constructs. Our analysis shows that all hypotheses regarding the direct influence of user experience on satisfaction ( $\mathrm{H} 1)$, product characteristics on satisfaction $(\mathrm{H} 2)$, user experience on satisfaction (H3), as well as user experience on satisfaction (H4), can be confirmed.

The collected data show that all independent variables have a strong impact on satisfaction with a search engine. Here, satisfaction with the core product, (e. g. technical possibilities, search results), has the strongest impact. It is followed by brand aspects, such as sympathy, trust, and loyalty, which are highly significant and have strong effects. User experience as a factor is significant as well, but does not have as high an impact.

Furthermore, we can show that customer satisfaction powerfully influences customer loyalty (H6). 
Table 4. Estimation results (direct effects)

\begin{tabular}{lllll}
\hline Adj. $\mathbf{R}^{\mathbf{2}}=\mathbf{0 . 6 3 7}$ & Path coefficient & t-value & p-value & Result \\
\hline H1: UX $\rightarrow$ Satisfaction & 0.267 & 5.452 & 0.000 & Supported \\
H2: Product $\rightarrow$ Satisfaction & 0.397 & 7.733 & 0.000 & Supported \\
H3 Brand $\rightarrow$ Satisfaction & 0.273 & 7.211 & 0.000 & Supported \\
H4: UX $\rightarrow$ Brand & 0.533 & 8.585 & 0.000 & Supported \\
H5: Product $\rightarrow$ Brand & 0.056 & 0.873 & 0.383 & Not supported \\
H6: Satisfaction $\rightarrow$ Loyalty & 0.820 & 38.877 & 0.000 & Supported \\
\hline
\end{tabular}

\subsection{Mediation Effects}

In addition to the examination of direct effects, the analysis considers whether the constructs have an indirect effect on increase of customer satisfaction (Table 5). Thus, we explore whether the brand image has a mediating effect with regard to the influence of the perceived product experience, and the user experience on customer satisfaction (H7 and H8).

In this context, the perception of such factors as: "Effort to achieve goals", "Design", or "Easy to use" might be summed up over time and, therefore, affect brand perception. Therefore, Hypothesis 7 can be supported.

Product related features, such as technical possibilities, "search results", "additional products", or "filters" do not have an impact on brand perception and are not mediated by the brand in order to have indirect impact on customer satisfaction. Hypothesis 8 can, therefore, not be supported.

Table 5. Estimation results (mediation)

\begin{tabular}{lllll}
\hline & Path coefficient & t-value & p-value & Result \\
\hline H7: Product $\rightarrow$ Brand $\rightarrow$ Satisfaction & 0.015 & 0.836 & 0.403 & Not supported \\
H8: UX $\rightarrow$ Brand $\rightarrow$ Satisfaction & 0.146 & 5.704 & 0.000 & Supported \\
\hline
\end{tabular}

In addition to analysis of direct and mediating effects, we tested for moderations to assess the impact of technological infrastructures as proxy lock-in-effects. Thus, we tested for moderating effects of the search engine preset within a browser on the impact of the brand, the product, and user experience on customer satisfaction (H9, H10, H11, Table 6).

We see that the effect of brand strength is moderated materially by the search engine default settings in the users' browsers, though at a relatively low level (H9). We therefore observe a particularly determined and amplifying lock-in effect, which can reinforce the already existing market power of established providers. While the brand effects are multiplied by technological preset, the perception of the product and user experience is not (H10 and H11).

Table 6. Estimation results (moderation)

\begin{tabular}{lllll}
\hline & Path coefficient & t-value & p-value & Result \\
\hline H9: Preset / Brand $\rightarrow$ Satisfaction & 0.087 & 2.257 & 0.024 & Supported \\
H10: Preset / Product $\rightarrow$ Satisfaction & -0.056 & 0.977 & 0.329 & Not supported \\
H11: Preset / UX $\rightarrow$ Satisfaction & -0.042 & 0.762 & 0.446 & Not supported \\
\hline
\end{tabular}

\section{Conclusion and Implications}

Our research shows that brand perception, product quality, and ease of use significantly influence customer satisfaction and inclination toward future usage of search engines. In this context, we see that satisfaction is, of course, strongly determined by observable product characteristics, such as website usability, (e. g. efficient goal achievement, site structure, design, ease of use), and product performance indicators, (e. g. perceived quality of search results, variety of products, filter functions). Furthermore, brand image is crucial, meaning that established brands certainly have a strong competitive advantage over new entrants since satisfaction with, and future usage of, a search engine is vitally determined by past experiences. This effect is even more intensified if the search 
engine is integrated into the browser infrastructure in advance. Conversely, it can be assumed that the specific evaluation of product characteristics plays a greater determining role in customer satisfaction and loyalty if search engines are not integrated into the browser infrastructure via preset and, therefore, allow users freedom of choice to clearly evaluate and use a search engine.

We can see at a glance that minimal competition in the German search engine market is further exacerbated by strong brands integrated within the technological infrastructure in a number of different ways. They are insulated from new market entrants by the fact that the image of (existing) brands as well as ease of use (in terms of browser presets and long habituated usage patterns) tends to inhibit consumers from being able to positively evaluate and use new offers, even though they may have the same quality standards regarding key product features as the wellestablished brands. These sorts of lock-in effects intensify already existing market entry barriers and make it highly challenging for new search engine providers to achieve success. Market entrants are forced to invest heavily in activities like communication and advertisement to break through, become well known, and trusted. What's more, new brands must invest significantly in distribution strategies, to enable integration into infrastructures in various browsers and operating systems among different services and internet enabled devices.

Initially, these activities cause high fixed costs before a new search engine provider can even compete, much less achieve financial success. Therefore, new entrants into the search engine market might need external support from different types of industry partners and associations, as well as social, academic, or political partners in the form of marketing support, (e.g. implementation of signaling and screening mechanisms), direct or indirect financial grants, as well as reduction of market entrance barriers based on specific competition policy interventions into platform economies. Particular measures at different industry levels should be evaluated in future research.

Future research should also incorporate larger and more diverse samples with which to focus more on the integration of different age groups, or non-users to better analyze in depth the reasons for adopting or avoiding search engine usage in general. Furthermore, our sample only includes the most common search engines in Germany. An integration of more services from different countries might yield additional and more detailed insights.

\section{References}

Aaker, D.A. (1996). Measuring brand equity across products and markets. California Management Review, 38(2), 102-112. https://doi.org/10.2307/41165845

ARD-ZDF-Forschungskommission. (2020). Ergebnisse der ARD/ZDF-Onlinestudie 2019. Retrieved from http://ard-zdfonlinestudie.de/files/2019/Ergebnispraesentation_ARD_ZDF_Onlinestudie_PUBLIKATION_extern.pdf

Bagozzi, R., P., \& Yi, T. (1988). On the evaluation of structural equation models. Journal of the Academy of Marketing Science, 16(1), 74-94. https://doi.org/10.1007/BF02723327

Bailey, P., Thomas, P., \& Hawking, D. (2007). Does brand name influence perceived Search result quality? Yahoo!, Google, and WebKumara. $12^{\text {th }}$ Australasian Document Computing Symposium.

Broschart, S. (2011). Suchmaschinenoptimierung \& Usability - Website-Ranking und Nutzerfreundlichkeit verbessern. Poing: Franzis.

Chin, W. W. (1998). The partial least squares approach to structural equation modeling, in: G. A. Marcoulides (Eds), Modern methods for business research (pp. 295-358.). Mahwah: Psychology Press.

Everhart, E. (2014). The evolution of SERPS and user behaviors. Retrieved from http://searchenginewatch.com/sew/how-to/2374414/the-evolution-ofserps-and-user-behaviors.

Fahrig, T. (2014). Suchmaschinen - Eine industrieökonomische Analyse der Konzentration und ihrer Ursachen. Ilmenau: Technische Universität Ilmenau.

Fornell, C., Larcker, D. F. (1981). Evaluating structural equation models with unobservable variables and measurement error. Journal of Marketing Research, 18, 39-50. https://doi.org/10.2307/3151312.

Henseler, J., Ringle, C., Sarstedt, M. (2015). A new criterion for assessing discriminant validity in variance-based structural equation modeling. Journal of the Academy of Marketing Science, 43, 115-135. https://doi.org/10.1007/s11747-014-0403-8

Heskett, J., Sasser, W., \& Schlesinger, L. (1997). The service profit chain. New York: Free Press.

Höchstötter, N., \& Koch, M. (2009). Standard Parameters for Searching Behaviour in Search Engines and their empirical Evaluation. Journal of Information Science, 35(1), 45-65. 
https://doi.org/10.1177/0165551508091311

Hugger, K. U. (2008). Uses-and-Gratification-Approach und Nutzenansatz. In Sander, U., von Gross, F., Hugger, K. U. (Eds.), Handbuch Medienpädagogik (pp. 173-178). Wiesbaden: Springer VS.

Jansen, B. J., Zhang, M., \& Schultz, C. D. (2009). Brand and its Effect on User Perception of Search Engine Performance. Journal of the American Society for Information Science and Technology, 60(8), 1572-1579. https://doi.org/10.1002/asi.21081

Jansen, B. J., Zhang, M., \& Zhang, Y. (2007). The Effect of Brand Awareness on the Evaluation of Search Engine Results. CHIEA, 7, 2471-2476.

Katz, E., Blumler, J. G., \& Gurevitch, M. (1974). Utilization of Mass Communication by the individual. In J. G. Blumler, K. E. (Eds.), Uses of Mass Communication (pp. 19-32). Beverly Hills: Sage.

Katz, E., \& Foulkes, D. (1962). On the Use of the Mass Media as 'escape' - Clarification of a Concept. Public Opinion Quarterly, 377-388. Volume?

Keller, K. L. (1993). Conceptualizing, Measuring, and Managing Customer-based Brand Equity. Journal of Marketing, 57(1), 1-22. https://doi.org/10.2307/1252054

Lance, C. E., Butts, M. M., \& Michels, L. C. (2006). The Sources of Four Commonly Reported Cutoff Criteria. What Did They Really Say? Organizational Research Methods, 9, 202-220. https://doi.org/10.1177/1094428105284919

Lewandowski, D. (2013). Challenges for search engine retrieval effectiveness evaluations: Universal Search and user intents, and results presentation. In G. Pasi, B. G., \& L. Jain (Eds.), Quality issues in the Management of Web Information (pp. 179-196). Berlin Heidelberg: Springer.

Lewandowski, D. (2014). Wie lässt sich die Zufriedenheit der Suchmaschinennutzer mit ihren Suchergebnissen erklären? In Krah, H., \& Müller-Terpitz, R. (Eds.), Suchmaschinen (pp. 35-52). Berlin, Berlin: Logos.

Lewandowski, D. (2015). Suchmaschinen verstehen. Berlin Heidelberg: Springer.

Lewandowski, D., \& Höchstötter, N. (2007). Qualitätsmessung bei Suchmaschinen. Informatik-Spektrum, 30(3), 159-169. https://doi.org/10.1007/s00287-007-0152-x

McCarthy, E. J. (1960). Basic Marketing: A Managerial Approach. Homewood: Irwin Professional Publishing.

Nunnally, J. C. (1978). Psychometric theory. New York: McGraw-Hill.

Paal, B. P. (2013). Markt- und Meinungsmacht der Suchmaschinen. In Krah H., Müller-Terpitz, R. (Eds.), Suchmaschinen (pp. 11-34). Berlin: Logos.

Palanisamy, R. (2013). Evaluation of Search Engines: A Conceptual Model and Research Issues. International Journal of Business and Management, 8(6), 1-15. https://doi.org/10.5539/ijbm.v8n6p1

Palmgreen, P., \& Rayburn, J. D. (1982). Gratifications Sought and Media Exposure. An Expectancy Value Model. Communications Research, 9(4), 561-580. https://doi.org/10.1177/009365082009004004

Palos-Sanchez, P., Martin-Velicia, F., \& Ramon Saura, J. (2018). Complexity in the Acceptance of Sustainable Search Engines on the Internet: An Analysis of Unobserved Heterogeneity with FIMIX-PLS. Complexity, (Special Issue), 1-19. https://doi.org/10.1155/2018/6561417

Pauly-Grundmann, D. (2010). Markenbewertung - Der objektivierte Markenwert unter besonderer Berücksichtigung des Income Approach. Wiesbaden: Springer.

Peris, M., \& Nüttgens, M. (2011). Anwendung der Unified Theory of Acceptance and Use of Technology zur Akzeptanzbestimmung von Web 2.0-Anwendungen in KMU-Netzwerken. 6th Conference on Professional Knowledge Management: From Knowledge to Action.

Quirmbach, S. M. (2012). Suchmaschinen - User Experience, Usability und nutzerzentrierte Website-Gestaltung. Berlin Heidelberg: Springer Vieweg.

Reyes-Menendez, A., Saura, J. R., Palos-Sanchez, P. R., \& Alvarez-Garcia, J. (2018). Understanding User Behavioral Intention to Adopt a Search Engine that Promotes Sustainable Water Management. Symmetry, 10, $1-21$.

Ringle, C. M., Wende, S., \& Will, A. (2020). Smartpls. Retrieved from http://www.smartpls.de

Rosengren, K. E., Wenner, L. A., \& Palmgreen, P. (1985). Media Gratifications Research: Current Perspectives. Beverly Hills: Sage. 
Schäfer, S., Pittner, N., Magin, M., \& Stark, B. (2015). Google: Alles nur Marke? Eine experimentelle Untersuchung zur Qualitätsbewertung von Suchmaschinen-Trefferlisten aus der Nutzerperspektive. In Pagel, S. (Ed.), Schnittstellen (in) der Medienökonomie (pp. 240-256). Baden-Baden: Nomos.

Sirdeshmukh, D., Ahmad, N. B., Khan, M. S., \& Ashill, N. J. (2018). Drivers of user loyalty, intention and commitment to a search engine: An exploratory study. Journal of Retailing and Consumer Services, 44, 7181. https://doi.org/10.1016/j.jretconser.2018.06.002

Speicher, M., Both, A., \& Gaedke, M. (2015). S.O.S.: Does Your Search Engine. CHI, 15, 1005-1014.

StatCounter (2020). Search Engine Market Share Worldwide. Retrieved from https://gs.statcounter.com/searchengine-market-share

Venkatesh, V., Thong, J. Y. L., \& Xu, X. (2012). Consumer Acceptance and Use of Information Technology: Extending the Unified Theory of Acceptance and Use of Technology. MIS Quarterly, 36(1), 157-178. https://doi.org/10.2307/41410412

Wong, K. K. K. (2016). Mediation analysis, categorical moderation analysis, and higher-order constructs modeling in partial least squares structural equation modeling (PLS-SEM): A B2B example using SmartPLS. The Marketing Bulletin, 26, 1-22.

\section{Copyrights}

Copyright for this article is retained by the author(s), with first publication rights granted to the journal.

This is an open-access article distributed under the terms and conditions of the Creative Commons Attribution license (http://creativecommons.org/licenses/by/4.0/). 